\title{
A clinical study on ruptured uterus: assessment of treatment approach and maternal and fetal outcome
}

\author{
Nilesh Dalal, Mansi Tiwari* \\ Department of Obstetrics and Gynecology, Mahatma Gandhi Memorial Medical College and M. Y. Hospital, Indore, \\ Madhya Pradesh, India
}

Received: 27 September 2018

Accepted: 22 October 2018

*Correspondence:

Dr. Mansi Tiwari,

E-mail: dr.mansitiwarigupta@gmail.com

Copyright: $\odot$ the author(s), publisher and licensee Medip Academy. This is an open-access article distributed under the terms of the Creative Commons Attribution Non-Commercial License, which permits unrestricted non-commercial use, distribution, and reproduction in any medium, provided the original work is properly cited.

\begin{abstract}
Background: Uterine rupture is a grave condition which is almost fatal for fetus. Various factors contribute to rupture uterus which include poor socioeconomic condition, uncontrolled fertility, illiteracy, adolescent marriage and contracted pelvis. The main objective of the study was to evaluate the incidence of rupture uterus, its etiology, risk factors, complications, treatment strategies, maternal and fetal outcome and to test the association between cause of rupture uterus and gravidity

Methods: This study was conducted over a period of 2 years from July 2015 to August 2017, in the Department of Obstetrics and Gynecology, M.Y. Hospital Indore (M.P.). All cases of rupture uterus, who were either admitted with or who developed this complication in the hospital, were included in the study. Diagnosis was made on history and examination and was confirmed on laparotomy.

Results: In this study the incidence of rupture uterus was $0.289 \%$. Total number of deliveries conducted during this period was 21782 and number of cases with rupture uterus were 63 . About $90 \%$ of cases belong to age group of 21-30 years. About $62 \%$ of cases belong to rural area and $81 \%$ of cases were unbooked. In the study $41 \%$ of cases were third gravida and $27 \%$ were second gravida. About $46 \%$ cases with previous 1 section and $20.7 \%$ cases came with obstructed labour. About $17.4 \%$ and $4.4 \%$ underwent Subtotal and Total hysterectomy respectively. However,78\% cases underwent repair of uterine tear.

Conclusions: All patients with primary caesarean section MUST have institutional deliveries. Patients who wish to; and have a favorable condition should be offered TOL (trial of labour) for VBAC, but under strict vigilance.
\end{abstract}

Keywords: Rupture uterus, TOL, VBAC

\section{INTRODUCTION}

Complete uterine rupture is a rare peripartum complication, often associated with a catastrophic outcome for both mother and child. ${ }^{1}$ A scarred uterus, because of a previous cesarean delivery substantially increases the risk of uterine rupture. ${ }^{1,2}$ Various factors reported in literature, which are associated with increased risk of uterine rupture include congenital uterine anomaly, grand multiparity, previous uterine surgery, fetal macrosomia, fetal malposition, labor induction, obstructed labor, uterine instrumentation, attempted forceps delivery, external version, and uterine trauma. ${ }^{3-5}$ Spontaneous uterine rupture is an extremely rare event, estimated to occur in one of 8,000 to one of 15,000 deliveries. ${ }^{6}$

Due to multiple reasons including, lack of health education, ignorance, or poverty; significant proportion of women in our country do not get regular antenatal check-up, preferring home delivery by traditional birth attendant instead of visiting the hospital. They visit the 
hospital in emergency situation after prolonged dysfunctional labor when traditional birth attendant fails to deliver the baby. The prolonged dysfunctional (obstructed) labor increases the risk of uterine rupture and rupture of previous cesarean scar. ${ }^{7}$ Continuous rising trend of cesarean deliveries has increased the number of women exposed to the risk of a rupture uterus.

\section{METHODS}

This study was conducted retrospectively over a period of 2 Years from July 2015 to August 2017, in the Department of Obstetrics and Gynecology, M.Y. Hospital Indore (M.P.). Total number of deliveries conducted during this period was 21782 .

\section{Procedure}

Patient's demographic variables like age, place of residence (rural/urban), socio economic status, parity, antenatal care in present pregnancy, clinical presentation, previous detailed obstetric and surgical history including previous cesarean sections, the type and indications for cesarean sections, myomectomy, dilatation and curettage were recorded. Physical examination including the vital signs, obstetric examination, details of labor in present pregnancy, blood group, hemoglobin estimation and urine examination were done in all the cases.

The site and type of the rupture, nature of surgery performed, duration of hospital stay, number of units of blood transfused, maternal and fetal outcome were documented. Rupture was labeled as complete when the entire thickness of uterine wall along with visceral peritoneum had given way, irrespective of extrusion of fetal parts. All other types were grouped under incomplete rupture. Incidence of rupture was calculated from total number of deliveries that had occurred in the hospital during the study period.

\section{Source of data}

All cases of rupture of uterus treated in Department of Obstetrics and Gynecology, M.Y. Hospital Indore (M.P.) during the period of 2 years from July 2015 to August 2017.

\section{Inclusion criteria}

- Complete, incomplete rupture and scar dehiscence

- Cases of rupture uterus occurring during Ante partum and Intrapartum period.

- Pregnancy in anomalous uterus leading to uterine rupture.

\section{Exclusion criteria}

- Iatrogenic rupture uterus both in scarred and unscarred uterus.
- Traumatic rupture due to fall or road traffic accident in both scarred and unscarred uterus.

\section{Different operations done in this study}

- Uterine wound repair with (or) without sterilization

- Subtotal hysterectomy

- Total abdominal hysterectomy

- Uterine wound repair with bladder repair.

\section{Statistical analysis}

Information of cases under study is arranged in a systematic manner in MS-Excel sheet. Appropriate statistical analysis viz. frequencies, cross tabulations, percentages, Chi-square test is carried out using SPSS version. 20 and the conclusions made as per the respective levels of significance.

\section{RESULTS}

The incidence of rupture uterus was $0.289 \%$ in our hospital. The incidence of rupture was $0.156 \%$ in women with history of prior uterine surgery and was $0.13 \%$ in women without history of any prior uterine surgery. Among the cases with history of prior uterine surgery, all the patients had prior low transverse cesarean section (Table 1).

Table 1: Incidence rate.

\begin{tabular}{|l|l|}
\hline Incidence & $\%$ of incidence \\
\hline Total number of deliveries & 21782 \\
\hline Total number of rupture uterus & 63 \\
\hline Incidence rate & 0.289 \\
\hline
\end{tabular}

Maximum cases were found to be in the age group of 21 to 30 years. This proves that pregnancy and cesarean section are occurring at a lower age than expected (Table 2).

Table 2: Age distribution of cases.

\begin{tabular}{|l|l|l|}
\hline Age (in years) & Number of cases & $\%$ of cases \\
\hline $21-25$ & 29 & 46 \\
\hline $26-30$ & 28 & 44 \\
\hline $31-35$ & 6 & 10 \\
\hline$>35$ & 0 & 0 \\
\hline
\end{tabular}

Most of the cases i.e. $62 \%$ were from rural area. This highlights the lack of education in rural part our country. Still people are ignorant about the aftermaths of pregnancy and its complications.

People still fail to seek help in institutions and rely on traditional birth attendants for their delivery and hence face the brunt of its complications (Table 3 ). 
Table 3: No. of cases of rupture uterus according to area.

\begin{tabular}{lll} 
Residence & No. of cases & Incidence \\
\hline Rural & 39 & $62 \%$ \\
\hline Urban & 24 & $38 \%$ \\
\hline
\end{tabular}

Fifty-one patients $(81 \%)$ were unbooked in our hospital and only $12(19 \%)$ were booked cases. One of the major causes is illiteracy still prevalent despite government programs to decrease it. Unbooked status leads to lack of early diagnosis and its management (Table 4).

Table 4: Incidence of rupture uterus in booked and unbooked population.

\begin{tabular}{|lll|}
\hline Antenatal care & No. of cases & Incidence \\
\hline Booked & 12 & $19 \%$ \\
\hline Unbooked & 51 & $81 \%$ \\
\hline
\end{tabular}

The average age of gravidity was 3 . Most of the patients were in labor at the time of rupture. Four patients with prior one lower segment cesarean section were not in labor at the time of rupture and 3 patients came after delivery at peripheral hospital. None of the patients were induced. The multiparous uterus in third and fourth gravida is more prone for rupture, especially in the presence of cephalopelvic disproportion (Table 5).

Table 5: Distribution of cases according to gravidity.

\begin{tabular}{|lll|}
\hline Gravidity & No. of cases & Incidence \\
\hline Gravida 1 & 5 & $8 \%$ \\
\hline Gravida 2 & 17 & $27 \%$ \\
\hline Gravida 3 & 26 & $41 \%$ \\
\hline Gravida 4 & 9 & $14 \%$ \\
\hline Gravida 5 & 1 & $1.5 \%$ \\
\hline Gravida 6 & 2 & $3.8 \%$ \\
\hline Post-natal status & 3 & $4.7 \%$ \\
\hline
\end{tabular}

In $54 \%$ cases, the cause of rupture uterus was previous 1 and previous 2 lower segment cesarean section. $24 \%$ cases were due to obstructed labor. 2 cases (3\%) had rupture of rudimentary horn of uterus. 1 case came with uterine inversion with rupture. This reflects the increasing trends of cesarean section and increase in CSMR (cesarean section on maternal request) (Table 6).

Table 6: Causes of rupture uterus.

\begin{tabular}{|lll|}
\hline Causes of rupture uterus & No. of cases & Incidence \\
\hline Previous 1 section & 29 & $46 \%$ \\
\hline Previous 2 section & 5 & $8 \%$ \\
\hline Obstructed labor & 13 & $20.7 \%$ \\
\hline $\begin{array}{l}\text { Obstructed labor with } \\
\text { hydrocephalus }\end{array}$ & 2 & $3.4 \%$ \\
\hline Malpresentation & 11 & $17.6 \%$ \\
\hline Rudimentry horn & 2 & $3 \%$ \\
\hline Uterine inversion & 1 & $1.5 \%$ \\
\hline
\end{tabular}

The clinical presentation of the patients with rupture of the unscarred uterus was more dramatic with extensive tears, hypotension, and shock. Rupture of scarred uterus, on the other hand, was usually incomplete and transverse (Table 7).

Table 7: Clinical features in cases of rupture uterus.

\begin{tabular}{|lll|}
\hline Clinical features & $\begin{array}{l}\text { No. of } \\
\text { cases }\end{array}$ & Percentage \\
\hline Pallor & 59 & 93.6 \\
\hline Dehydration & 40 & 63.4 \\
\hline Tachycardia & 40 & 63.4 \\
\hline Hypotension & 10 & 15.8 \\
\hline Cold clammy skin & 10 & 15.8 \\
\hline Per abdominal examination & & \\
\hline Abdominal distension & 18 & 28.5 \\
\hline Absent fetal heart sound & 61 & 96.8 \\
\hline $\begin{array}{l}\text { Palpation of superficial fetal } \\
\text { parts }\end{array}$ & 56 & 88.8 \\
\hline Loss of uterine contour & 56 & 88.8 \\
\hline Cessation of uterine contraction & 55 & 87.3 \\
\hline Abdominal tenderness & 48 & 76.1 \\
\hline Vaginal bleeding & 16 & 25.3 \\
\hline Hematuria & 23 & 36.5 \\
\hline
\end{tabular}

Intraoperatively, the estimated blood loss ranged from 1,200 to $1,500 \mathrm{cc}$. Hemoperitoneum was identified in $96 \%$ of the patients. Almost all patients received blood transfusion either intraoperatively or postoperatively. The choice of surgical procedure was based upon the type, location, and extent of tear; patient's hemodynamic status; and desire for future fertility. 78 percent of the patient underwent repair of rent with or without bladder repair and simultaneous tubal ligation. Rent repair required less operative time and was considered a better option for patients who wanted to preserve fertility. Subtotal hysterectomy was performed in 11 cases and total hysterectomy in 3 cases, where repair was not possible (Table 8).

Table 8: Surgical management in cases of rupture uterus.

\begin{tabular}{|lll|}
\hline Type of surgery & No. of cases & Percentage \\
\hline Hysterectomy & 14 & 22 \\
\hline Total hysterectomy & 3 & 4.7 \\
\hline Subtotal hysterectomy & 11 & 17.4 \\
\hline With bladder repair & 4 & 6.3 \\
\hline Without bladder repair & 10 & 15.8 \\
\hline Repair of tear & 49 & 78 \\
\hline With bladder repair & 11 & 17.4 \\
\hline Without bladder repair & 38 & 60.3 \\
\hline With bilateral tubectomy & 12 & 19 \\
\hline
\end{tabular}

The fetal outcome was poor as described in (Table 9). There were 32 cases of intrauterine fetal demise and five cases of stillbirths. 2 babies were live but had low Apgar scores. One of them died in neonatal intensive care unit 
(NICU). Postoperatively, the most common complication was urinary tract infection seen in $38.2 \%$ of patients. Second most common complication was febrile morbidity seen in $29 \%$ of patients.

Table 9: Perinatal outcome.

\begin{tabular}{|lll|}
\hline Perinatal outcome & No. of cases & Percentage \\
\hline Live birth & 02 & 3.1 \\
\hline Still birth & 06 & 9.5 \\
\hline Intrauterine death & 55 & 87.3 \\
\hline
\end{tabular}

Other less common complications are described in (Table 10). Despite the presence of grave maternal complications, no maternal death occurred in our series.

Table 10: Post-operative complication.

\begin{tabular}{|ll|}
\hline Complications & Rate of complications \\
\hline Urinary tract infection & $38.2 \%$ \\
\hline Fever & $29 \%$ \\
\hline Wound infection & $12.5 \%$ \\
\hline Shock & $8.8 \%$ \\
\hline Respiratory tract complication & $10 \%$ \\
\hline DIC & $1.5 \%$ \\
\hline
\end{tabular}

\section{DISCUSSION}

Rupture of the gravid uterus is an unexpected, rare, and potentially life-threatening devastating complication. It still constitutes one of the most serious obstetrical emergencies. ${ }^{8}$ Despite the advances of modern medicine, it continues to cause adverse fetal and maternal health consequences. The incidence of one in 345 deliveries $(0.289 \%)$ for uterine rupture in our series is similar to that reported in previous publications. ${ }^{9-11}$ Maximum cases were found to be in the age group of 21 to 30 years. This was similar to study conducted by Sunitha et al. ${ }^{12}$ In this study $81 \%$ of the cases were unbooked which is comparable to $80 \%$ in the study by Rashmi et al. ${ }^{12}$

Present study not only confirmed several important independent risk factors for uterine rupture, including previous cesarean section, multiparity, malpresentations, and labor dystocia; but also demonstrated that four major risk factors (history of prior uterine surgery, grand multiparity, obstructed labor, and fetal malpresentations) contributed to more than $90 \%$ cases of uterine rupture. The single risk factor (history of prior cesarean section) contributed to $54 \%$ cases of uterine rupture. This is comparable to the study by Sahu L in which $50 \%$ of ruptures involved a previous scar. ${ }^{13}$ Therefore, a great degree of caution should be taken while managing patients with previous uterine scar who are attempting trial of labor. Repeat cesarean delivery should be strongly considered in women with previous scarred uterus, if their Friedman's labor curve deviates from normal. Hamilton et al., reported that with labor dystocia (i. e., cervical dilatation lower than the 10th percentile and arrest for more than $2 \mathrm{~h}$ ), cesarean delivery prevents more than $42.1 \%$ cases of uterine rupture. ${ }^{14}$

The most common predisposing factors for rupture uterus reported in literature are grand multiparity, obstetrical trauma, fetal macrosomia and malpresentations. ${ }^{3-5}$ However, in our patient population, the most common risk factor was prior cesarean delivery. Thus, with the continued rising trend of cesarean section, the number of women presenting to the labor ward with a scarred uterus is increasing, thereby exposing them to an increased risk for maternal morbidity, including uterine rupture. ${ }^{15}$

The risk of uterine rupture differs significantly depending on the type of the prior incision (low transverse, low vertical, classical, or unknown). A prospective observational study of 45,988 women with a singleton gestation estimates uterine rupture rates of $0.7 \%$ for low transverse incisions, $2.0 \%$ for low vertical incisions, and $0.5 \%$ for unknown scars. ${ }^{16}$ A clinical challenge is presented in the patients with an unknown prior scar. Given the circumstances surrounding the delivery, obstetricians should infer which type of uterine incision is most likely in this group of patients. The risk of rupture with a T-shaped or classical incision is much higher, and ranges from 4 to $9 \% .{ }^{17}$ The consequences of this potentially life-threatening condition depend on the time that has elapsed from the occurrence of rupture until the definitive management. Prompt maternal supportive and resuscitative measures should be undertaken to avoid catastrophic consequences like life-threatening uterine hemorrhage and maternal shock.

Once the rupture uterus is diagnosed, prompt management is the essence. Patient, if in clinical shock needs immediate resuscitation and surgical intervention. After the situation is fully evaluated, obstetrician then needs to decide if the rupture is surgically reparable or hysterectomy is needed. The choice of the surgical procedure also depends upon the type, location, and the extent of the uterine tear. Several authors considered subtotal or total hysterectomy as procedure of choice; whereas, others recommend that surgical repair is a safer immediate treatment. ${ }^{18,19}$ In present study, successful repair were achieved in $78 \%$ of cases. However, repair of ruptured uterus increases the possibility of recurrence of rupture in subsequent pregnancies, with reported incidence of $4.3-19 \% .^{20,21}$ Therefore, elective repeat cesarean delivery should be performed in this group of patients. Extensive counseling regarding future pregnancy and potentially associated complications should always be done with the patient.

Controversy exists in the literature regarding maternal mortality. Present study and many other studies did not find any maternal death after a uterine rupture. ${ }^{3}$ However, the Definitive therapy for the fetus is delivery via emergent surgical intervention, which is helpful in avoiding or reducing major fetal morbidities including fetal hypoxia, anoxia, acidosis, and fetal mortality. 
Delivery within $30 \mathrm{~min}$ after the uterine rupture is suspected clinically is associated with good long-term neonatal outcomes. ${ }^{22}$ However, majority of our patients were unbooked and were transferred to the hospital in emergency after obstructed labor or uterine rupture was suspected. The time delay between onset of rupture and delivery contributed to high neonatal mortality, as demonstrated in present study. Adequate transportation facilities should be available with primary care centers so that these patients can be transferred to higher centers immediately.

Early identification of non-reassuring fetal heart rate patterns can help the obstetrician to suspect uterine rupture early. However, there is lack of availability of electronic fetal monitors in majority of the institutions in our country. We presume that once continuous electronic fetal monitoring facilities are more readily available, incidence of grave maternal and neonatal consequences can be reduced. Present study was limited due to its retrospective nature. We were only able to review the information that was adequately documented in patient records. We could not evaluate the time lost in transportation of the patient to our hospital after the uterine rupture was clinically suspected at outside facility and effect of this time delay on the neonatal outcome.

\section{CONCLUSION}

All patients with primary caesarean section MUST have institutional deliveries. Patients who wish to; and have a favorable condition should be offered TOL (trial of labor) for VBAC, but under strict vigilance. Contraceptive counselling is must beginning right from antenatal care, intranatal and postnatal period. Increased accessibility to good obstetric care and prompt referral system to equipped facilities with availability of transportation services is essential for developing countries to avoid these catastrophic emergencies. Primary health care providers should undergo a special training to deal with patients of cesarean deliveries and to identify the imminent signs of rupture so that they can be referred at the earliest.

\section{ACKNOWLEDGMENTS}

Authors would like to thank HOD, Dept. of obstetrics and gynecology, M.Y. Hospital Indore for permitting to report the hospital data.

\section{Funding: No funding sources}

Conflict of interest: None declared

Ethical approval: The study was approved by the Institutional Ethics Committee

\section{REFERENCES}

1. Ofir K, Sheiner E, Levy A, Katz M, Mazor M. Uterine rupture: risk factors and pregnancy outcome. Am J Obstet Gynecol. 2003;189(4):1042-6.
2. Smith JG, Mertz HL, Merrill DC. Identifying risk factors for uterine rupture. Clin Perinatol. 2008;35(1):85-99.

3. Farmer RM, Kirschbaum T, Potter D, Strong TH, Medearis AL. Uterine rupture during trial of labor after previous cesarean section. Am J Obstet Gynecol. 1991;165(4):996-1001.

4. Miller DA, Diaz FG, Paul RH. Vaginal birth after cesarean: A 10-year experience. Obstet Gynecol. 1994;84(2):255-8.

5. Nkemayim DC, Hammadeh ME, Hippach M, Mink $\mathrm{D}$, Schmidt W. Uterine rupture in pregnancy subsequent to previous laparoscopic electromyolysis. Case report and review of the literature. Arch Gynecol Obstet. 2000;264(3):154-6.

6. Miller DA, Goodwin TM, Gherman RB, Paul RH. Intrapartum rupture of the unscarred uterus. Obstet Gynecol. 1997;89(5):671-3.

7. Mahbuba D, Alam IP. Uterine rupture - Experience of 30 cases at Faridpur medical college hospital. Faridpur Med Coll J. 2012;7(2):79-81.

8. Eden RD, Parker RT, Gall SA. Rupture of the pregnant uterus: A 53-year review. Obstet Gynecol. 1986;68(5):671-4.

9. Gardeil F, Daly S, Turner MJ. Uterine rupture in pregnancy reviewed. Eur J Obstet Gynecol Reprod Biol. 1994;56(2):107-10.

10. Waterstone M, Bewley S, Wolfe C. Incidence and predictors of severe obstetric morbidity: Case-control study. BMJ. 2001;322(7294):1089-93.

11. Sunitha K, Indira I, Suguna P. Clinical study of rupture uterus-Assessment of Maternal and fetal outcome. J Den Med Sci. 2015;14(3):39-45.

12. Rashmi G, Radhakrisknan NB, Vaid N. Agarwal. Rupture uterus--changing Indian scenario. J Indian Med Assoc. 2001;99(11):634-7.

13. Sahu L. A 10-year analysis of uterine rupture at a teaching institution. $\mathrm{J}$ Obstet Gynaecol India. 2006;56(6):502-06.

14. Hamilton EF, Bujold E, McNamara H, Gauthier R, Platt RW. Dystocia among women with symptomatic uterine rupture. Am J Obstet Gynecol. 2001;184(4):620-4.

15. Chazotte C, Cohen WR. Catastrophic complications of previous cesarean section. Am J Obstet Gynecol. 1990;163(3):738-42.

16. Landon MB, Hauth JC, Leveno KJ, Spong CY, Leindecker S, Varner MW, et al. National Institute of Child Health and Human Development MaternalFetal Medicine Units Network. Maternal and perinatal outcomes associated with a trial of labor after prior cesarean delivery. $\mathrm{N}$ Engl $\mathrm{J}$ Med. 2004;351(25):2581-9.

17. American College of Obstetricians and Gynecologists. ACOG Practice bulletin no. 115: Vaginal birth after previous cesarean delivery. Obstet Gynecol. 2010;116:450-63.

18. Garnet JD. Uterine rupture during pregnancy. An analysis of 133 patients. Obstet Gynecol. 1964;23(6):898-905. 
19. Garnet JD. Uterine rupture during pregnancy. An analysis of 133 patients. Obstet Gynecol. 1964;23(6):898-905.

20. Sheth SS. Results of treatment of rupture of the uterus by suturing. J Obstet Gynaecol Br Commonw. 1968;75(1):55-8.

21. Agüero O, Kizer S. Obstetric prognosis of the repair of uterine rupture. Surg Gynecol Obstet. 1968;127(3):528-30.

22. Holmgren C, Scott JR, Porter TF, Esplin MS, Bardsley $\mathrm{T}$. Uterine rupture with attempted vaginal birth after cesarean delivery: Decision-to-delivery time and neonatal outcome. Obstet Gynecol. 2012;119(4):725-31.

Cite this article as: Dalal N, Tiwari M. A clinical study on ruptured uterus: assessment of treatment approach and maternal and fetal outcome. Int $\mathbf{J}$ Reprod Contracept Obstet Gynecol 2018;7:5020-5. 